\title{
Patterns of epidermal growth factor receptor mutation in non-small-cell lung cancers in the Gulf region
}

\author{
ABDUL RAHMAN JAZIEH ${ }^{1}$, HASAN JAAFAR ${ }^{2}$, MOHAMMED JALOUDI $^{2}$, RASHA SALEH MUSTAFA $^{3}$, \\ KAKIL RASUL $^{4}$, JAMAL ZEKRI ${ }^{5}$, HANAA BAMEFLEH ${ }^{1}$ and AHMED GASMELSEED ${ }^{1}$ \\ ${ }^{1}$ Department of Oncology, King Saud bin Abdulaziz University for Health Sciences, King Abdullah International \\ Medical Research Center, National Guard Health Affairs, Riyadh 11426, Kingdom of Saudi Arabia; ${ }^{2}$ Department of \\ Oncology, Tawam Hospital, Al Ain 15258, United Arab Emirates; ${ }^{3}$ King Fahd Medical City, Riyadh 11525 , \\ Kingdom of Saudi Arabia; ${ }^{4}$ Department of Oncology, Al Amal Hospital, Doha 3050, Qatar; ${ }^{5}$ Department of \\ Oncology King Faisal Specialist and Research Center, Riyadh 11211, Kingdom of Saudi Arabia
}

Received May 15, 2015; Accepted August 12, 2015

DOI: $10.3892 / \mathrm{mco} .2015 .644$

\begin{abstract}
The aim of the present study was to determine the prevalence of epidermal growth factor receptor mutations (EGFRmut) in the Gulf region (GR) and its correlation with demographic and clinical characteristics. A multisite retrospective study was conducted, including institutions from Saudi Arabia, the United Arab Emirates and Qatar. All consecutive patients with non-small-cell lung cancer tested for EGFRmut were eligible. Data collected included demographic information, disease characteristics and EGFR test results. Data on 230 patients were obtained. The median age of the patients was 61 years (range, 26-87 years); 169 patients (69.83\%) were male and 204 (88.7\%) were Arab. The histological subtype was adenocarcinoma in 191 (83.4\%) and squamous cell carcinoma in 21 cases $(9.17 \%)$. Overall, EGFRmut were detected in 66 patients $(28.7 \%)$, with a prevalence of $32.46 \%$ in adenocarcinoma. No squamous cell carcinomas were found to harbor EGFRmut. The univariate and multivariate analyses revealed that female gender, non-smoking status and adenocarcinoma subtype were significant predictors for EGFRmut. There was no difference between Arabs and non-Arabs. In conclusion, to the best of our knowledge, this is the first multisite study to report the prevalence of EGFRmut in the GR population, which was found to be higher compared with that in Western, but lower compared with that in Far Eastern populations. Studies evaluating the efficacy of targeted therapy in this population are underway.
\end{abstract}

Correspondence to: Dr Abdul Rahman Jazieh, Department of Oncology, King Saud bin Abdulaziz University for Health Sciences, King Abdullah International Medical Research Center, P.O. Box 22490, Riyadh 11426, Kingdom of Saudi Arabia

E-mail: jazieha@ngha.med.sa

Key words: non-small-cell lung cancer, epidermal growth factor receptor, Gulf region

\section{Introduction}

Targeting epidermal growth factor receptor (EGFR) is a significant advancement in the management of non-small-cell lung cancer (NSCLC) (1). Although the use of tyrosine kinase inhibitors (TKIs) in clinical practice preceded the unraveling of the association between EGFR mutations (EGFRmut) and clinical benefit (2-5), the identification of EGFRmut helped in advancing the field rapidly from patient selection based on clinical characteristics to molecular profile-based selection (6), resulting in improved outcome, ability to use the targeted agents in the first-line setting, and understanding the mechanism underlying resistance to treatment, thereby optimizing planning to overcome treatment failure $(7,8)$.

The prevalence of EGFRmut exhibits ethnic variations, as it is more frequent in Asian populations compared with Caucasians (9). Furthermore, EGFRmut are usually encountered in adenocarcinomas, whereas they are rarely detected in squamous cell lung cancer.

The prevalence of EGFRmut in the population of the Gulf region (GR) has not been reported. The aim of the present study was to report the results of the first large multisite study, including 3 countries in the GR.

\section{Patients and methods}

Study design. A retrospective study was conducted through reviewing medical records and extracting the required information. Consecutive patients with metastatic NSCLC who were tested for EGFRmut were included in this study. EGFR testing was performed using quantitative polymerase chain reaction analysis in accredited laboratories. Data from 6 centers in 3 GR countries, including the Kingdom of Saudi Arabia, United Arab Emirates and Qatar, were included.

The data collection form contained different data elements, including demographic, clinicopathological, and brief treatment data. Demographic patient information included age, gender, race and smoking status. Disease-related information included date of diagnosis, immunohistochemistry 
Table I. Demographics and clinical characteristics $(n=230)$.

\begin{tabular}{lr}
\hline Characteristics & No. $(\%)$ \\
\hline Median age, years (range) & $61(26-87)$ \\
Race & \\
Arab & $204(88.70)$ \\
Non-Arab & $26(11.30)$ \\
Gender & \\
Male & $162(70.43)$ \\
Female & $68(29.57)$ \\
Smoking status & \\
Smokers & $96(41.74)$ \\
Non-smokers & $134(58.26)$ \\
Histology & \\
Adenocarcinoma & $191(83.41)$ \\
Squamous cell carcinoma & $21(9.17)$ \\
Large-cell carcinoma & $2(0.87)$ \\
Others & $16(6.55)$ \\
Survival status & \\
Deceased & $95(41.30)$ \\
Alive & $135(58.70)$ \\
\hline
\end{tabular}

results and histological subtype. Data from molecular studies included the presence and type of mutation and the exon it affected.

First-, second- or third-line treatment selection and whether chemotherapy or TKIs were administered were also recorded. Survival data including vital status and date of death were also obtained.

This study was conducted after Institutional Review Board approval was obtained from all the participating institutions.

Statistical analysis. The statistical analysis software SAS version 9.2 (SAS Institute, Cary, NC, USA) was applied for data analysis and $\mathrm{P} \leq 0.05$ was considered to indicate statistically significant differences. All collected variables were described using descriptive and analytical inferential statistics. Categorical variables were described as counts and percentages. Continuous variables were described as mean, median, standard deviation and range. Survival analysis was performed using the Kaplan-Meier method, while univariate and multivariate analyses were applied to investigate the association of EGFRmut with demographic and clinical characteristics.

\section{Results}

Patient characteristics. A total of 230 patients were enrolled in this study. The demographic and clinical characteristics of the study cohort are summarized in Table I. Of note, the majority of the patients were non-smokers and males.

EGFRmut analysis. EGFRmut were detected in 66 patients (28.70\%), whereas exon 19 abnormalities consti-
Table II. Results of EGFR mutation analysis $(n=230)$.

\begin{tabular}{lr}
\hline Characteristics & No. $(\%)$ \\
\hline EGFR & \\
Positive & $66(28.70)$ \\
Negative & $164(71.30)$ \\
Adenocarcinoma $(\mathrm{n}=191)$ & $62(32.46)$ \\
EGFR-positive & \\
Squamous cell carcinoma $(\mathrm{n}=21)$ & $0(0.00)$ \\
EGFR-positive & \\
Large-cell carcinoma, NOS $(\mathrm{n}=2)$ & $0(0.00)$ \\
EGFR-positive & \\
Others (n=16) & $4(25.00)$ \\
EGFR-positive & $4 *(6.06)$ \\
Exon 18 abnormality & $36(54.54)$ \\
Exon 19 abnormality & $26(39.40)$ \\
Exon 21 abnormality mutation L858R &
\end{tabular}

* One patient had concurrent mutation on Exon 20. EGFR, epidermal growth factor receptor; NOS, not otherwise specified.

tuted more than half of the cases (54.54\%); exon 21 mutations accounted for $39.40 \%$ of the cases, followed by exon 18 abnormalities $(6.06 \%)$; one patient had mutations on exon 18 and exon 20 (Table II).

None of the 21 squamous cell carcinomas harbored EGFRmut, which makes their prevalence 32.46 and $25.00 \%$ in adenocarcinoma and other types, respectively (Table II).

Treatment. The treatment pattern for EGFRmut patients in Table III revealed that 38 patients $(54.29 \%)$ received TKIs as first-line treatment and a total of $27.27 \%$ of patients with wild-type EGFR received TKIs as any-line treatment.

Multivariate analysis for the association of EGFRmut with demographic and clinical characteristics. The univariate analysis revealed that adenocarcinoma subtype, female gender and non-smoking status were significantly associated with EGFRmut (93.51 vs. $79.14 \%, \mathrm{P}=0.0049 ; 46.75$ vs. $22.42 \%$, $\mathrm{P}=0.0001$; and 81.82 vs. $48.48 \%, \mathrm{P}=0.0001$, respectively; data not shown). On the multivariate analysis, all these previously mentioned variables remained significant as independent predictive factors of EGFRmut status (Table IV).

Survival. The median survival was 24.9 months (95\% CI: 19.4-36.3) for EGFRmut patients compared with 17.2 months (95\% CI: 10.4-26.5) in EGFR-negative cases $(\mathrm{P}=0.0132$ ) (Fig. 1) Hazard regression analysis for survival revealed that only EGFRmut was significantly correlated with better outcome $(\mathrm{HR}=0.618, \mathrm{CI}: 0.384-0.994$ and $\mathrm{P}=0.047$ ) (Table V). Patients who harbored EGFRmut and received TKI fared significantly better in terms of survival compared with the remaining patients, with a median survival of 24.93 months (95\% CI: 19.43-36.33) and 17.24 (10.43-26.53), respectively ( $\mathrm{P}=0.0253)$ (Fig. 2). 
Table III. Use of EGFR inhibitors in the first-, second- and third-line setting according to EGFR status (n=230).

\begin{tabular}{|c|c|c|c|c|c|c|}
\hline EGFR status & No. & $\begin{array}{c}\text { First-line, } \\
\text { no. }(\%)\end{array}$ & $\begin{array}{l}\text { Second-line, } \\
\text { no. }(\%)\end{array}$ & $\begin{array}{c}\text { Third-line, } \\
\text { no. }(\%)\end{array}$ & $\begin{array}{c}\text { Fourth-line, } \\
\text { no. }(\%)\end{array}$ & $\begin{array}{l}\text { Not used, } \\
\text { no. }(\%)\end{array}$ \\
\hline Mutant & 66 & $38(54.29)^{\mathrm{a}}$ & $16(22.86)^{\mathrm{a}}$ & $3(4.28)^{\mathrm{a}}$ & $3(4.28)^{\mathrm{a}}$ & $10(14.29)^{\mathrm{b}}$ \\
\hline Wild-type & 164 & $19(11.52)$ & $16(10.31)$ & $6(3.63)$ & $3(1.81)$ & $121(72.73)$ \\
\hline
\end{tabular}

${ }^{\mathrm{a}} \mathrm{A}$ total of 4 mutant and one wild-type patient received first-line erlotinib (Tarceva) and further-line gefitinib. ${ }^{\mathrm{b}}$ One test done on archive after patient death, one discussed with primary oncologist and started on treatment, and 8 unknown reasons. EGFR, epidermal growth factor receptor.

Table IV. Multivariate analysis for the association of EGFR mutation with demographic and clinical characteristics $(\mathrm{n}=230)$.

\begin{tabular}{|c|c|c|c|}
\hline Characteristics & OR & $95 \% \mathrm{CI}$ & P-value \\
\hline \multicolumn{4}{|l|}{ Gender } \\
\hline Female vs. male & 2.074 & $1.057-4.068$ & 0.034 \\
\hline \multicolumn{4}{|l|}{ Race } \\
\hline Arab vs. non-Arab & 1.302 & $0.492-3.450$ & 0.595 \\
\hline \multicolumn{4}{|l|}{ Smoking status } \\
\hline Non-smokers vs. smokers & 3.348 & $1.581-7.091$ & 0.002 \\
\hline \multicolumn{4}{|l|}{ Histology } \\
\hline AdenoCa vs. others & 3.842 & $1.242-11.889$ & 0.019 \\
\hline \multicolumn{4}{|l|}{ Immunohistochemistry } \\
\hline CK20, positive vs. negative & 0.716 & $0.185-2.768$ & 0.629 \\
\hline TTF-1, positive vs. negative & 24.633 & $3.300-183.847$ & 0.002 \\
\hline
\end{tabular}

EGFR, epidermal growth factor receptor; OR, odds ratio; CI, confidence interval; $\mathrm{Ca}$, carcinoma; $\mathrm{CK}$, cytokeratin; TTF, thyroid transcription factor.

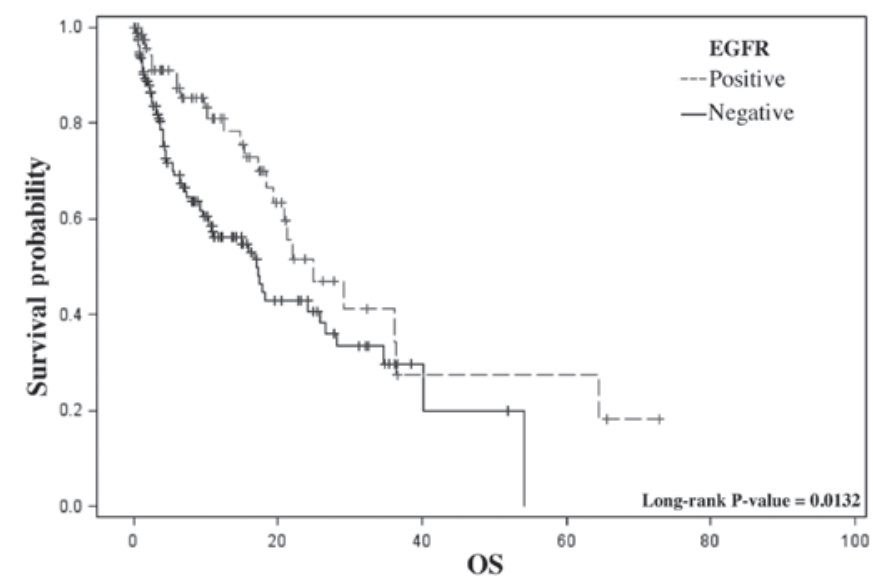

Figure 1. Overall survival (OS) analysis for patients with epidermal growth factor receptor (EGFR) mutations vs. EGFR wild-type.

\section{Discussion}

To the best of our knowledge, the present study is the largest regional multisite and multi-country study to investigate the prevalence of molecular targets in NSCLC. This study revealed
Table V. Hazard regression analysis for demographic and clinical characteristics $(n=230)$.

\begin{tabular}{lccc}
\hline Variables & HR & $95 \%$ CI & P-value \\
\hline $\begin{array}{l}\text { Race } \\
\quad \text { Arab vs. non-Arab }\end{array}$ & 2.211 & $0.889-5.498$ & 0.088 \\
$\begin{array}{l}\text { Gender } \\
\text { Female vs. male }\end{array}$ & 0.890 & $0.519-1.525$ & 0.671 \\
$\begin{array}{l}\text { Smoking history } \\
\quad \text { Non-smokers vs. smokers }\end{array}$ & 0.871 & $0.538-1.411$ & 0.575 \\
$\begin{array}{l}\text { Histology } \\
\quad \text { AdenoCa vs. others }\end{array}$ & 0.666 & $0.397-1.117$ & 0.123 \\
$\begin{array}{l}\text { EGFR mutation } \\
\quad \text { Present vs. absent }\end{array}$ & 0.618 & $0.384-0.994$ & 0.047 \\
\hline
\end{tabular}

HR, hazard ratio; CI, confidence interval; Ca, carcinoma; EGFR, epidermal growth factor receptor.

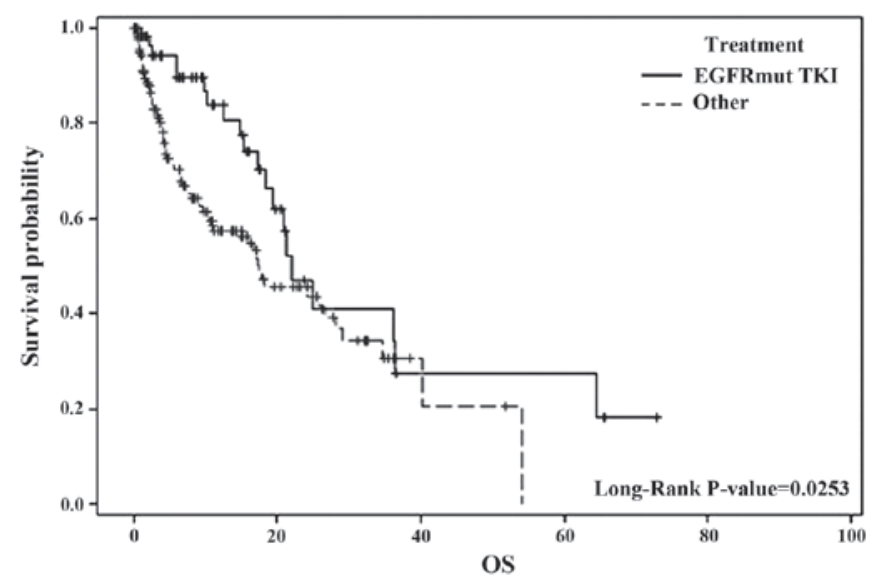

Figure 2. Overall survival (OS) analysis for patients with epidermal growth factor receptor mutations (EGFRmut) receiving tyrosine kinase inhibitors (TKI) vs. all others (56 vs. 170, respectively; $\mathrm{n}=226$ ).

a prevalence of EGFRmut in one-third of patients with lung adenocarcinoma. This EGFRmut prevalence rate was found to be higher compared with that of the Western population ( 20\%), but lower compared with that in Far Eastern populations $(\sim 40-50 \%)$. The geographical location and racial and ethnic background in the GR differs significantly from the other two populations; therefore, the prevalence is expected to be different. 
The lower prevalence of smoking in our patient population may be another reason for the higher mutation rate in our patient cohort compared with that in Western populations.

Other studies from a single institution or country revealed a lower mutation rate, as in a recent study of 137 patients from Morocco, which reported a mutation rate of $20 \%$ (10). In another study on 106 Lebanese patients with adenocarcinoma, only $8.5 \%$ harbored EGFRmut (11). Variations between countries in this region may be attributed to potential variations in ethnicity and prevalence of smoking. Previously reported predictors of EGFRmut or response to TKI therapy include female gender, adenocarcinoma histology and non-smoking status, which was consistent with our findings. However, a significant proportion of male patients and smokers also harbor EGFRmut. This fact makes clinical selection criteria for testing impractical, since, if testing was to be limited to non-smokers and/or female patients, a significant proportion of patients harboring the mutation would be missed.

The prognostic value of EGFRmut has been previously reported, as patients with mutations fare better compared with patients with wild-type tumors. As expected, patients who received TKI treatment had a better outcome compared with the remaining patients $(11,12)$.

Approximately $13 \%$ of the patients with EGFRmut did not receive TKIs, possibly due to lack of access to healthcare or poor patient condition.

This study had certain limitations due to the retrospective nature of its design. The patients included in the study were only those who were actually tested for EGFRmut, who were possibly selected by the treating physician based on clinical or demographic characteristics, which may differentiate them from the total lung cancer population; this may explain the long overall survival for both groups. However, to minimize selection bias in our study, we included consecutive patients tested for EGFRmut; hence, over two-thirds of our patients were male and $40 \%$ were smokers. We considered it important to obtain data on all lung cancer patients at the institution, including whether they were tested, as well as the reasons for not being tested. This concept is currently under evaluation in an ongoing study in the GR.

In conclusion, EGFRmut were encountered in a significant fraction of patients with non-squamous cell lung cancer in the GR.

Further prospective studies are required (some are currently ongoing) to evaluate all lung cancer patients for druggable targets, as well as studies investigating the efficacy and safety of TKIs in this patient population.

\section{Acknowledgements}

The authors wish to acknowledge the efforts of Ms. Nagham Sheblaq, Study Coordinator, and Mr. Tabrez Pasha, Data Manager, from the King Abdulaziz Medical City.

\section{References}

1. Ciardiello $\mathrm{F}$ and Tortora G: EGFR antagonists in cancer treatment. N Engl J Med 358: 1160-1174, 2008.

2. Fukuoka M, Yano S, Giaccone G, Tamura T, Nakagawa K, Douillard JY, Nishiwaki Y, Vansteenkiste J, Kudoh S, Rischin D, et al: Multi-institutional randomized phase II trial of gefitinib for previously treated patients with advanced non-small-cell lung cancer (The IDEAL 1 Trial) [corrected] $\mathrm{J}$ lin Oncol 21: 2237-2246, 2003. [corrected].

3. Kris MG, Natale RB, Herbst RS, Lynch TJ Jr, Prager D, Belani CP, Schiller JH, Kelly K, Spiridonidis H, Sandler A, et al: Efficacy of gefitinib, an inhibitor of the epidermal growth factor receptor tyrosine kinase, in symptomatic patients with non-small cell lung cancer: A randomized trial. JAMA 290: 2149-2158, 2003.

4. Sato M, Shames DS, Gazdar AF and Minna JD: A translational view of the molecular pathogenesis of lung cancer. J Thorac Oncol 2: 327-343, 2007.

5. Cohen MH, Williams GA, Sridhara R, Chen G, McGuinn WD Jr, Morse D, Abraham S, Rahman A, Liang C, Lostritto R, et al: United States Food and Drug Administration Drug Approval summary: Gefitinib (ZD1839; Iressa) tablets. Clin Cancer Res 10: 1212-1218, 2004.

6. Lynch TJ, Bell DW, Sordella R, Gurubhagavatula S, Okimoto RA, Brannigan BW, Harris PL, Haserlat SM, Supko JG, Haluska FG, et al: Activating mutations in the epidermal growth factor receptor underlying responsiveness of non-small-cell lung cancer to gefitinib. N Engl J Med 350: 2129-2139, 2004.

7. Kobayashi S, Boggon TJ, Dayaram T, Jänne PA, Kocher O, Meyerson M, Johnson BE, Eck MJ, Tenen DG and Halmos B: EGFR mutation and resistance of non-small-cell lung cancer to gefitinib. N Engl J Med 352: 786-792, 2005.

8. Bean J, Brennan C, Shih JY, Riely G, Viale A, Wang L, Chitale D, Motoi N, Szoke J, Broderick S, et al: MET amplification occurs with or without T790M mutations in EGFR mutant lung tumors with acquired resistance to gefitinib or erlotinib. Proc Natl Acad Sci USA 104: 20932-20937, 2007.

9. Shi Y, Au JS, Thongprasert S, Srinivasan S, Tsai CM, Khoa MT, Heeroma K, Itoh Y, Cornelio G and Yang PC: A prospective, molecular epidemiology study of EGFR mutations in Asian patients with advanced non-small-cell lung cancer of adenocarcinoma histology (PIONEER). J Thorac Oncol 9: 154-162, 2014.

10. Errihani H,Inrhaoun H, Boukir A, Kettani F, Gamra L, Mestari A, Jabri L, Bensouda Y, Mrabti H and Elghissassi I: Frequency and type of epidermal growth factor receptor mutations in Moroccan patients with lung adenocarcinoma. J Thorac Oncol 8: 1212-1214, 2013.

11. Fakhruddin N, Mahfouz R, Farhat F, Tfayli A, Abdelkhalik R, Jabbour M, Yehia L, Mahfoud Z and Zaatari G: Epidermal growth factor receptor and KRAS mutations in lung adenocarcinoma: A retrospective study of the Lebanese population. Oncol Rep 32: 2223-2229, 2014.

12. Sonobe M, Kobayashi M, Ishikawa M, Kikuchi R, Nakayama E, Takahashi T, Menju T, Takenaka K, Miyahara R, Huang CL, et al: Impact of KRAS and EGFR gene mutations on recurrence and survival in patients with surgically resected lung adenocarcinomas. Ann Surg Oncol 19 (Suppl 3): S347-S354, 2012. 